\title{
Review
}

\section{Mixed Depression: A Mini-Review to Guide Clinical Practice and Future Research Developments}

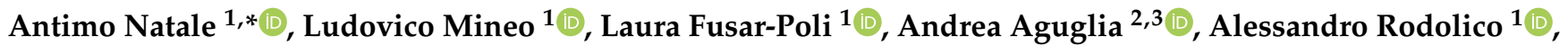 \\ Massimo Tusconi ${ }^{4}{ }^{(\mathbb{D}}$, Andrea Amerio $\left.{ }^{2,3}{ }^{(}\right)$, Gianluca Serafini ${ }^{2,3}{ }^{(}$, Mario Amore $^{2,3}$ and Eugenio Aguglia ${ }^{1}(\mathbb{D}$ \\ 1 Psychiatry Unit, Department of Clinical and Experimental Medicine, University of Catania, \\ 95123 Catania, Italy; ludwig.mineo@gmail.com (L.M.); laura.fusarpoli@gmail.com (L.F.-P.); \\ alessandro.rodolico@phd.unict.it (A.R.); eugenio.aguglia@unict.it (E.A.) \\ 2 Section of Psychiatry, Department of Neuroscience, Rehabilitation, Ophthalmology, Genetics, \\ Maternal and Child Health, University of Genoa, 16126 Genoa, Italy; andrea.aguglia@unige.it (A.A.); \\ andrea.amerio@unige.it (A.A.); gianluca.serafini@unige.it (G.S.); mario.amore@unige.it (M.A.) \\ 3 IRCCS Ospedale Policlinico San Martino, 16132 Genoa, Italy \\ 4 Section of Psychiatry, Department of Medical Sciences and Public Health, University of Cagliari, \\ 09042 Cagliari, Italy; massimotusconi@yahoo.com \\ * Correspondence: antimo.natale88@gmail.com
}

check for

updates

Citation: Natale, A.; Mineo, L.;

Fusar-Poli, L.; Aguglia, A.; Rodolico,

A.; Tusconi, M.; Amerio, A.; Serafini,

G.; Amore, M.; Aguglia, E. Mixed

Depression: A Mini-Review to Guide

Clinical Practice and Future Research

Developments. Brain Sci. 2022, 12, 92.

https://doi.org/10.3390/

brainsci12010092

Academic Editor: Marcin Siwek

Received: 15 December 2021

Accepted: 7 January 2022

Published: 11 January 2022

Publisher's Note: MDPI stays neutral with regard to jurisdictional claims in published maps and institutional affiliations.

Copyright: (C) 2022 by the authors. Licensee MDPI, Basel, Switzerland. This article is an open access article distributed under the terms and conditions of the Creative Commons Attribution (CC BY) license (https:/ / creativecommons.org/licenses/by/ $4.0 /)$.

\begin{abstract}
The debate on mixed states (MS) has been intense for decades. However, several points remain controversial from a nosographic, diagnostic, and therapeutic point of view. The different perspectives that have emerged over the years have turned into a large, but heterogeneous, literature body. The present review aims to summarize the evidence on MS, with a particular focus on mixed depression $(\mathrm{MxD})$, in order to provide a guide for clinicians and encourage the development of future research on the topic. First, we review the history of MS, focusing on their different interpretations and categorizations over the centuries. In this section, we also report alternative models to traditional nosography. Second, we describe the main clinical features of $\mathrm{MxD}$ and list the most reliable assessment tools. Finally, we summarize the recommendations provided by the main international guidelines for the treatment of MxD. Our review highlights that the different conceptualizations of MS and MxD, the variability of clinical pictures, and the heterogeneous response to pharmacological treatment make $\mathrm{MxD}$ a real challenge for clinicians. Further studies are needed to better characterize the phenotypes of patients with MxD to help clinicians in the management of this delicate condition.
\end{abstract}

Keywords: mixed states; mixed depression; mood; bipolar disorder; psychomotor agitation; review; Koukopoulos

\section{Introduction}

For centuries, there has been a continuous debate on mixed states (MS). Nevertheless, the co-existence of elements belonging to opposite polarities in the same clinical picture, the variability of manifestations and complications, as well as the peculiar pharmacological treatment, still make MS a challenge for clinicians. Several points remain controversial. First, it is difficult to systemize MS within the common nosographic systems, as they could be considered either as independent entities or be collocated along a spectrum ranging from pure depression to pure mania. Second, it is unclear which symptoms need to be encompassed in the clinical picture and which scales and diagnostic criteria should be adopted in clinical practice for a prompt identification of MS. Third, there is scant evidence of the most effective pharmacological treatment in both acute-phase management and maintenance. Notably, the most up-to-date guidelines have difficulty in systematizing these entities and providing precise indications for clinicians [1]. For these reasons, the present review aims to comprehensively summarize the evidence on MS, with a particular focus on mixed depression $(\mathrm{MxD})$, in order to provide a guide for clinicians and to encourage the development of research studies in the future. 


\section{Brief Historical Overview of the Concept}

The concept of manic-depressive illness, including MS, was originally formulated in classical medicine, starting with Hippocrates (ca. 460-370 B.C.) and Aretaeus of Cappadocia (ca. 30-130 A.C.) [2,3]. The earliest evidence of an established MS can be found in ancient medical manuals as well as in 18th-century treatises on psychopathology, although the first conceptual and terminological definitions only date back to the 19th century $[4,5]$.

In the field of psychiatry, among the pioneers of the exploration of MS, Heinroth-in his work entitled "Disorders of Mental Life or Mental Disorders"—used the German term "Mischungen" ("mix or mixture") to identify psychopathological conditions difficult to classify because of the coexistence of contrasting affective elements [6]. Wilhelm Griesinger, another German psychiatrist, described states of mental alteration characterized by the coexistence of melancholic and manic elements and distinguishable from rapid cycling forms and seasonal affective disorders. Griesinger defined those psychopathological conditions as "intermediate forms,", i.e., "melancholia with destructive impulses" and "melancholia with long-lasting exaltations of volition" [7].

Despite the contributions of previous psychiatrists in describing clinical pictures assimilated to the current concept of MS, Emil Kraepelin was the first author to systematize MS, including these conditions within the context of manic-depressive illness [8]. Indeed, Kraepelin and his pupil Weygandt conceived depressive and manic phases as the utmost of a unique disorder, namely manic-depressive illness [9], and considered MS as the most common forms of this disorder [10]. On the contrary, in the 1950s, Karl Leonhard posited a clear distinction between unipolar and bipolar disorder [11]. Modern nosography is fundamentally based on Leonhard's dichotomy [12]. Consequently, MS have only been studied marginally for decades.

\section{Mixed States in the DSM: From the Revolution of DSM-III to DSM-IV Mixed Episode}

In the first edition of the DSM (1952), MS were confined in a marginal position as part of the category "manic depressive reaction, other" [13]. The DSM-II (1968) introduced the category of "mixed manic-depressive illness", collocating it among "Other major affective disorders", describing it as a condition in which "manic and depressive symptoms appear almost simultaneously" [14].

In 1980, the DSM-III radically changed the classification of mood disorders, as Kraepelin's broad concept of manic-depressive insanity was separated into two distinct entities: bipolar disorder (BD) and major depressive disorder (MDD) [15]. This classification was adopted after Leonhard's dichotomy and did not take into account Kraepelin's conception of manic-depressive illness as a continuum [16]. Additionally, the DSM-III introduced the diagnostic category of "Bipolar disorder, mixed", defined as "current (or most recent) episode involving the full symptomatic picture of both manic and major depressive episodes, intermixed or rapidly alternating every few days." This definition was substantially retained in the DSM-III-R (1987), except for the duration criterion of two weeks for depressive symptoms [17]. In the DSM-IV and DSM-IV-TR, MS were incorporated into the diagnostic category of "mixed episode" $[18,19]$. According to DSM-IV-TR criteria, it was possible to diagnose a mixed episode in the co-presence of criteria to diagnose either a manic or major depressive episode (except for the time criterion) for at least one week. Therefore, a mixed episode could only be present in the case of a BD-I diagnosis and not in MDD or BD-II. In fact, manic episodes are pathognomonic for BD-I but not BD-II, which is instead characterized by an alternation of hypomanic and depressive episodes. The DSM-IV-TR operational definition of a mixed episode has proved to be extremely narrow, as it targeted an almost unrealistic clinical condition, failing to discriminate the most prevalent presentations of MS, i.e., sub-threshold forms characterized by the occurrence of few symptoms of the opposite polarity during the same affective episode [20,21]. 


\section{Current Nosographic Classification of Mixed Episodes and Mixed Depression}

The precise identification of a depressive episode with mixed characteristics is of great importance for the subsequent diagnostic framework and treatment planning because of the significantly worse course and the peculiar responsiveness to treatment [22]. The DSM-5 has represented, from this point of view, a significant step forward, with the introduction of the specifier "with mixed characteristics"; for the first time, this clarification has enabled the recognition of the possible co-presence of expansive and depressive symptoms during a depressive episode within a BD (Type I or Type II), or MDD [23]. Indeed, in the DSM-5, a depressive episode with mixed features can be diagnosed when "full criteria are met for a major depressive episode, and at least three manic/hypomanic symptoms are present during the majority of days of the current or most recent episode of depression". Of note, distractibility is not enumerated among manic/hypomanic symptoms that can appear during a mixed episode [24]. There is growing consensus that the introduction of the specifier of "mixed characteristics" may allow clinicians to describe mood disorders along a spectrum ranging from pure unipolar depression to pure mania [25].

Differently from the DSM-5, the 11th edition of the International Classification of Diseases (ICD-11), classifies MS as a separate diagnostic category. MS are defined as "the presence of several prominent manic and depressive symptoms consistent with those observed in manic episodes and depressive episodes, which either occur simultaneously or alternate very rapidly ..." [26]. It is specified that, when depressive symptoms predominate in a mixed episode, the most common contrapolar symptoms are irritability, distractibility, increased verbal production, and psychomotor agitation [27]. Therefore, unlike the DSM-5, the choice of maintaining a specific diagnostic category and including the overlapping symptoms may increase diagnostic sensitivity and ensure more targeted therapeutic strategies. Clinicians should also be aware that the ICD-11 introduced the diagnostic category "mixed depressive and anxiety disorder", which may represent a potential confounding factor. This category is defined as the co-presence of depressive and anxiety symptoms, not severe enough to warrant a diagnosis of depressive disorder or anxiety disorder [26]. Therefore, this diagnostic category does not deal with MS or MxD.

Some authors criticize the choice of both current nosographic models to propose a definition of MS that involves a combinatorial approach of symptoms of both polarities rather than specific profiles of different mixed episode subtypes. Indeed, the combinatorial approach would not be able to discriminate among the more serious clinical forms of MxD [28]. Another consideration must be made about the choice of including also the rapid alternation of the two polarities in the definition of $\mathrm{MxD}$. This makes it difficult to discriminate between a mixed episode and ultra-fast cycling (mood-changing states of polarity over weeks or days) and, in particular, ultradian cycling (mood changes occurring within a day) [29].

\section{The Concept of Mixed Depression and Alternative Models to Official Nosographic Categories}

Some authors disagree with the conceptualization of mixed depression (MxD) proposed by the DSM- 5 . The most relevant aspect is related to the set of diagnostic criteria proposed for the definition of $\mathrm{MxD}$, which, according to some authors, would be too narrow to include the entire spectrum of symptoms. One criticism is the absence of irritable mood and psychomotor agitation in the current DSM-5 diagnostic category of "depressive episode with mixed features" [30]. This is important because prevalence rates may vary depending on the definition of MxD used. For instance, a study by Miller et al. (2016) found that the use of narrower criteria (i.e., DSM-5) allowed them to identify $2.6 \%$ to $10.8 \%$ of MxD in a sample of patients with BD. Conversely, $14.9 \%$ could be diagnosed with MxD using broader criteria (i.e., the presence of subthreshold hypomania concurrent with at least mild depression) [31].

Koukopoulos' studies are among the proposed alternative models. In the early 1990s, Koukopoulos described a group of patients with apparently classical depression who 
did not respond to treatments with antidepressants. This group of patients manifested psychomotor agitation, insomnia, sometimes increased suicidal ideation, and psychotic symptoms. The main characteristics described were intense emotionality and the marked expression of feelings with crying crises and a cyclothymic or hyperthymic temperament [32]. Koukopoulos hypothesized that this presentation could originate from an excitatory process, as justified by the response to treatment with antiepileptics, neuroleptics, lithium, and electroconvulsive therapy [33]. In 2007, Koukopoulos proposed new diagnostic criteria for the classification of $\mathrm{MxD}$, including psychomotor agitation, irritability, and mood lability [34]. This classification was further validated by a larger clinical study [12,35]. In empirical studies, the frequency of mixed-mood states similar to the DSM-5 definition ranges from 7 to $12 \%$ [36]. In contrast, the inclusion of irritability and psychic or psychomotor agitation as central features of $\mathrm{MxD}$ increased the frequency of mixed mood states up to $47 \%$ [34]. For this reason, Koukopoulos and Sani suggested the possibility of renaming the clinical identity of these symptoms as "excitatory" instead of "manic", highlighting a different nature of this component than the pure manic symptom [34]. Of note, a recent multicenter study showed an overlapping discriminant capacity between traditional DSM-5 criteria and Koukopoulos' mixed-depression criteria [37]. Moreover, the cross-sectional, multinational study "Bipolar Disorders: Improving Diagnosis, Guidance and Education (BRIDGE)-II-MIX" called for the inclusion of symptoms such as psychomotor agitation, mood lability, hypersexuality, and aggressiveness in the DSM-5 specified for "mixed episodes" [23].

Benazzi, another Italian author that focused his research on MS, considered MxD within the dimensional approach of mood disorders. In contrast with Koukopoulos, the definition of MxD proposed by Benazzi refers to a minimum number of hypomanic symptoms (without specifying which one in particular) present within the depressive state [38]. According to the author, this definition would increase the diagnostic sensitivity of MxD [39]. The cut-off for a diagnosis of $\mathrm{MxD}$ is the presence of three symptoms of hypomania or a score $>=8$ in the Hypomania Interview Guide (HIG) during a depressive episode [40].

More recently, Mahli and colleagues proposed the Activity, Cognition, and Emotion (ACE) model as a possible approach for studying mood disorders. This model divides the different symptoms within the three dimensions, considering how they may vary over time. This model is in line with Kraepelin's conceptualization of manic-depressive illness as a spectrum [41]. Any symptoms within the domain can be considered as primary or secondary or described by a scale of severity from non-pathological to characterizing. This model allows a greater understanding of the pathophysiology underlying the disorder. In addition, it allows the conceptualization of the various subclinical aspects of clinical presentations by improving the recognition and understanding of mood disorders [41-45].

Unfortunately, at present, although the DSM-5 with the mixed specifier may add a feature to unipolar MxD, there is speculation that the presence of overlapping excitatory symptoms may more accurately describe a subgroup of patients with MDD with marked bipolar predisposition [22]. These considerations suggest the need for a significant revision of the specifier regarding depression with mixed features in the next revision of the DSM-5 [46].

\section{Mixed Depression in Clinical Practice: Diagnosis and Course of Illness}

The clinical characteristics of MxD are widely variable. Typically, depressive symptoms of mixed and non-mixed episodes substantially overlap in their clinical presentation and severity [47]. Negative self-evaluation, increased energy, and racing thoughts seem to be present in MxD [48]. High levels of anxiety characterize the clinical presentation of MxD, although its diagnostic usefulness is limited, because anxiety is also predominant in non-mixed depressive states [2]. The same applies to agitation, understood both as internal tension and motor restlessness. Indeed, several studies have shown the presence of agitation even in the case of non-MxD [49]. Psychotic symptoms may also occur in the clinical context of $\mathrm{MxD}$ [50]. In fact, patients who present mixed symptoms differ from 
those with pure forms by higher suicidality rates, higher relapse rates, the higher incidence of comorbidities, and lower rates of response to treatment.

Some works in the literature have reported that patients with $\mathrm{MxD}$ are more frequently females, show higher rates of medical and psychiatric comorbidities and fewer euthymic mood periods $[1,31]$. The pediatric population represent a poorly studied category which, however, seems at risk for the development of mixed symptoms. In fact, adolescents with $\mathrm{MxD}$ appear to have higher levels of disability, increased severity, and more comorbidities than adolescents with pure MDD or BD [51]. During depression, even a family history of BD or completed suicide could be indicative of the possible development of mixed symptoms and manic switch [52]. Finally, taking antidepressants during a depressive episode may represent an important cause of development of mixed symptoms (i.e., iatrogenic cause). In this case, the main guidelines recommend a careful reduction in the dosage or even a suspension of the antidepressant medication [1].

The combination of despair experiences with increased energy and impulsivity makes MxD patients more at risk for suicidal behavior [53]. High levels of anxiety can further increase the risk of suicide [54]. As reported by the DSM-5, patients with mixed features have to be strictly monitored and followed-up, as the presence of subthreshold manic symptoms represents a phenotypic indicator of a bipolar diathesis. Therefore, the presence of hypomanic symptoms may indicate a risk factor for a subsequent development of a BD [55].

Regardless of the risk of a possible transition to a full-blown $\mathrm{BD}$, the presence of mixed features in the context of a major depressive episode is associated with a more severe illness phenotype, with more likely mixed relapses.

\section{Psychometric Tools to Evaluate Mixed Depression}

Several scales have been identified to assess the presence and severity of (hypo)manic symptoms within the clinical presentation of psychiatric patients, such as the Young Mania Rating Scale (YMRS; [56]), the Internal State Scale (ISS; [57]), the Hypomania Checklist-32 (HCL-32; [58]), and the Altman Self-Rating Mania Scale (ASRM; [59]. Other scales, such as the Montgomery-Åsberg Depression Rating Scale (MADRS) or the Hamiton Depression Rating Scale (HAM-D) can be used to assess the presence and severity of depressive symptoms. The combination of scales for depression and mania can be useful for clinicians to assess the presence of MS even if they are not specifically designed for this purpose.

Interestingly, the Bipolar Disorder Rating Scale (BDRS, [60]) is an instrument specifically designed for bipolar depression. It is a semi-structured interview composed of 20 items, each with a score that can range from 0 to 3 for a maximum total of 60 points.

Indeed, only a few scales have been specifically created to identify (hypo)manic symptoms in the context of MxD. The Mini-International Neuropsychiatric Interview (MINI) consists of several modules that allow the identification of the main psychiatric diagnoses, with dichotomous items (yes/no). Recently, in the section that refers to depressive disorder, a subscale for $\mathrm{MxD}$ has been formulated [61]. This scale is self-rated by the patients.

The Clinically Useful Depression Outcome Scale with questions for DSM-5 Mixed subtype (CUDOS-M, [62]). It is a self-assessment scale developed by Zimmerman et al. (2014), which includes 13 items based on the DSM-5 specific criteria for MxD with satisfactory reliability and validity [63]. Each item of the scale is rated on a 5-point ordinal scale to indicate the frequency of symptoms during the past week $(0=$ not at all true [0 days]; 4 = almost always true [every day]), and the total score ranges from 0 to 52.

The Structured Clinical Interview for DSM (SCID) is a semi-structured interview organized into modules for formulating DSM-5 diagnoses [64]. In the latest version, in the section corresponding to depressive disorders, the symptomatology of $\mathrm{MxD}$ is also investigated.

The Koukopoulos Mixed Depression Rating Scale (KMDRS) was developed by Koukopoulos to evaluate the symptoms of MxD based on the criteria he proposed (i.e., the presence of a depressive episode plus irritability and internal tension, emotional lability, 
and absence of slowing down). The KMDRS is a self-administered scale, consisting of 14 items evaluating the presence and severity of the excitatory symptoms typical of MxD [65]. Moreover, Tavormina et al. recently developed the G.T. Mixed States Rating Scale (GTMSRS), a self-administered rating scale composed of 11 items, of which seven also include sub-items $[66,67]$.

Finally, the Clinical Monitoring Form (CMF) proposed by Sachs et al. may represent a useful, freely available tool in high-risk cases, such as patients with depressive symptoms and a family history of BD [68].

\section{Pharmacotherapy}

The pharmacological management of MS has always represented a challenge for clinicians who must balance the need to treat both manic and depressive symptoms with the risk of mood-switching. In fact, the use of antidepressant medications to treat depressive symptoms can induce a switch to mania [69]; conversely, a pharmacotherapy based on antipsychotics (especially in the case of strong D2 receptor blockers) may increase the risk of switching to depression $[70,71]$.

A further difficulty is that the available literature evidence is scant and weakened by important methodological limitations that affect randomized clinical trials. The evaluation of the response to medications of (hypo)manic patients with depressive symptoms is mainly based on the post-hoc or pooled analysis of randomized clinical studies originally meant to study treatment efficacy in manic episodes. Since the presence of contrapolar symptoms generally constitutes an exclusion criterion in trials conducted on subjects affected by major depressive episodes, the evidence for MxD is even more lacking. Hence, historically, pharmacotherapy of MS has represented an unmet need in the international guidelines for the treatment of mood disorders.

To date, only three international guidelines specifically address the treatment of MS: the Canadian Network for Mood and Anxiety Treatments (CANMAT) and the International Society for Bipolar Disorders (ISBD) recommendations (2021, [1]); the World Federation of Societies of Biological Psychiatry (WFSBP) guidelines (2019; [72]; the guidelines developed by Stahl and colleagues focused exclusively on MxD (2017; [73]). Moreover, treatment recommendations for episodes with mixed features are available in the updated editions of some international guidelines for BD: Evidence-based guidelines for treating bipolar disorder: revised third edition recommendations from the British Association for Psychopharmacology (2016; [74]); the International College of Neuro-Psychopharmacology (CINP) treatment guidelines for bipolar disorder in adults (2017; [75]); Royal Australian and New Zealand College of Psychiatrists (RANZCP) clinical practice guidelines for mood disorders (2021, [76]). The guidelines adopt different definitions of MS or MxD, which are displayed in Supplementary Table S1.

Despite their heterogeneity, all the guidelines agree upon avoiding the use of antidepressants in MxD in monotherapy. In cases in which an antidepressant is needed, they suggest combining it with a mood stabilizer or a second-generation antipsychotic (SGA). Of note, only Stahl's guidelines expressly include the use of antidepressants in combination with mood stabilizers or SGAs among the third-level recommendations (lithium or lamotrigine or valproate or atypical antipsychotic + bupropion; lithium or lamotrigine or valproate or atypical antipsychotic + selective serotonin reuptake inhibitors; lithium or lamotrigine or valproate or atypical antipsychotic + monoamine oxidase inhibitors).

SGAs are psychotropic agents that are generally considered as first-line or second-line choices in the treatment of acute depression with mixed features by most of the guidelines considered (Table 1). Among antipsychotics, olanzapine, lurasidone, and ziprasidone appear to have more evidence of efficacy in treating MxD [69]. The use of mood stabilizers, such as lithium or valproate, is recommended during the maintenance phase, although they can also be prescribed during the acute phase [73,76]. Finally, the usefulness of lithium in preventing suicide is evident: data show its efficacy even when it is not effective in preventing affective episodes [77]. 
Table 1. Pharmacological treatment for the acute phase of mixed depression (MxD).

\begin{tabular}{|c|c|c|c|c|c|c|c|c|c|c|}
\hline & \multicolumn{2}{|c|}{$\begin{array}{c}\text { CANMAT-ISBD: } \\
\text { DSM-5 }\end{array}$} & \multicolumn{2}{|c|}{$\begin{array}{l}\text { CANMAT-ISBD: } \\
\text { DSM IV }\end{array}$} & \multicolumn{2}{|c|}{ WFSBP } & \multicolumn{2}{|c|}{ CINP } & \multirow[t]{2}{*}{ RANZCP * } & \multirow[t]{2}{*}{ Stahl } \\
\hline & D & $\mathbf{M}$ & D & $\mathbf{M}$ & $\mathbf{M}$ & D & $\mathbf{M}$ & D & & \\
\hline First-line & & & $\begin{array}{l}\text { Asenapine, } \\
\text { aripiprazole }\end{array}$ & $\begin{array}{l}\text { Asenapine, } \\
\text { aripiprazole }\end{array}$ & & & & & $\begin{array}{l}\text { Lithium, } \\
\text { divalproex, } \\
\text { quetiapine }\end{array}$ & $\begin{array}{c}\text { Lurasidone, } \\
\text { asenapine, } \\
\text { quetiapine XR, } \\
\text { aripiprazole, } \\
\text { ziprasidone }\end{array}$ \\
\hline Second-line & $\begin{array}{l}\text { Cariprazine, } \\
\text { lurasidone }\end{array}$ & Cariprazine & $\begin{array}{c}\text { Olanzapine + } \\
\text { litium/divalproex, } \\
\text { carbamazepine } \\
\text { ER, olanzapine, } \\
\text { divalproex }\end{array}$ & $\begin{array}{c}\text { Olanzapine + } \\
\text { litium/divalproex, } \\
\text { carbamazepine } \\
\text { ER, olanzapine, } \\
\text { divalproex }\end{array}$ & & & Olanzapine + MS & Olanzapine + MS & $\begin{array}{l}\text { Cariprazine, } \\
\text { ziprasidone, } \\
\text { lurasidone }\end{array}$ & $\begin{array}{c}\text { Lamotrigine, } \\
\text { divalproex, } \\
\text { lithium, } \\
\text { cariprazine, } \\
\text { olanzapine; } \\
\text { MS + SGA; lithium + } \\
\text { divalproex; } \\
\text { lithium/divalproex + } \\
\text { lamotrigine; } \\
\text { olanzapine + fluoxetine }\end{array}$ \\
\hline Third-line & $\begin{array}{c}\text { Olanzapine, } \\
\text { olanzapine + } \\
\text { fluoxetine, } \\
\text { quetiapina, } \\
\text { divalproex, } \\
\text { lamotrigine, } \\
\text { ziprasidone, ECT }\end{array}$ & $\begin{array}{l}\text { Olanzapine, } \\
\text { quetiapina, } \\
\text { divalproex, } \\
\text { ziprasidone, ECT }\end{array}$ & $\begin{array}{c}\text { Ziprasidone, } \\
\text { divalproex }+ \\
\text { carbamazepine } \\
\text { ER, cariprazine, } \\
\text { Lithium }+ \\
\text { divalproex, ECT }\end{array}$ & & $\begin{array}{l}\text { Ziprasidone } \\
\text { (combination) }\end{array}$ & $\begin{array}{c}\text { Ziprasidone } \\
\text { (combination) }\end{array}$ & $\begin{array}{l}\text { Aripiprazole, } \\
\text { arbamazepine, } \\
\text { olanzapine }\end{array}$ & $\begin{array}{c}\text { Aripirazole, } \\
\text { carbamazepine, } \\
\text { olanzapine, } \\
\text { paliperidone, } \\
\text { risperidone, } \\
\text { valproate }\end{array}$ & $\begin{array}{l}\text { Carbamazepine, } \\
\text { Olanzapine }\end{array}$ & $\begin{array}{c}\text { Carbamazepine, } \\
\text { lithium + carba- } \\
\text { mazepine/pramipexole, } \\
\text { ECT, MS/SGA + } \\
\text { bupropion, } \\
\text { MS/SGA+ } \\
\text { SSRI/MAOI } \\
\end{array}$ \\
\hline $\begin{array}{l}\text { Insufficient } \\
\text { evidence }\end{array}$ & $\begin{array}{c}\text { Aripirazole, } \\
\text { asenapine, } \\
\text { carbamazepine, } \\
\text { Lithium, rTMS }\end{array}$ & $\begin{array}{l}\text { Olanzapine + } \\
\text { fluoxetine, } \\
\text { lamotrigine, } \\
\text { aripirazole, } \\
\text { asenapine, } \\
\text { carbamazepine, } \\
\text { lithium, rTMS, } \\
\text { lurasidone }\end{array}$ & $\begin{array}{c}\text { Lithium, } \\
\text { lurasidone, } \\
\text { quetiapine, } \\
\text { paliperidone, } \\
\text { risperidone, } \\
\text { risperidone + } \\
\text { lithium/divalproex, } \\
\text { rTMS }\end{array}$ & $\begin{array}{l}\text { Lithium, } \\
\text { quetiapine, } \\
\text { paliperidone, } \\
\text { risperidone, } \\
\text { risperidone + } \\
\text { lithium/divalproex, } \\
\text { rTMS }\end{array}$ & & & & $\begin{array}{l}\text { Paliperidone, } \\
\text { haloperidole+ MS, } \\
\text { risperidone + MS }\end{array}$ & $\begin{array}{c}\text { Lithium, } \\
\text { quetiapine, } \\
\text { haloperidol + MS, } \\
\text { risperidone + MS }\end{array}$ & \\
\hline
\end{tabular}

Legend: Guidelines: CANMAT—ISBD: Canadian Network for Mood and Anxiety Treatments—International Society for Bipolar Disorders; WFSBP: World Federation of Societies of Biological Psychiatry; CINP: International College of Neuropsychopharmacology; RANZGP: Royal Australian and New Zealand College of Psychiatrists; Abbreviations: D: depressive symptoms during acute mixed depression: ECT: electroconvulsive therapy; M: manic symptoms during acute mixed depression; MS: mood stabilizer; rTMS: repetitive transcranial magnetic stimulation; SGA: second-generation antipsychotic; SSRI: selective-serotonin reuptake inhibitor; MAOI: monoamine oxidase inhibitors; XR: extended release. * In the RANZGP guidelines, there are no levels of recommendations, but a flowchart of choices to follow according to the type of mixed episode and the prevalence of specific symptoms in each episode is provided. 


\section{Conclusions}

Our study aimed to provide a synthesis about $\mathrm{MxD}$ and guide clinicians' choices. The present review shows that current evidence is still unclear in several points. This uncertainty may be related to the lack of neurobiological and epidemiological studies based on recognized diagnostic criteria [78]. A better phenotyping of patients in clinical practice could solve many questions about the diagnostic orientation [79]. In this regard, the creation of clinical and research groups regarding MxD would favor the formulation of more sensitive and specific criteria for the identification of this condition. This may consequently lead to a personalization of care and treatment. In fact, the use of inappropriate medications, such as antidepressants, may worsen the clinical picture instead of ameliorating symptoms. Of note, longitudinal studies are warranted to evaluate whether the presence of mixed features in individuals with MDD may represent a warning for a potential evolution to BD. The present review shows that it is important for clinicians to remember that MxD is very common in clinical practice and is often associated with a worse outcome and high suicide risk. Future research should focus on these aspects to provide clear answers.

Supplementary Materials: The following supporting information can be downloaded at: https: / / www.mdpi.com/article/10.3390/brainsci12010092/s1, Table S1: Definition of mixed depression and inclusion criteria used in the main guidelines.

Author Contributions: Conceptualization, A.N. and L.M.; writing-original draft preparation, A.N., L.M., M.T.; writing-review and editing, L.F.-P., A.R., A.A. (Andrea Aguglia), A.A. (Andrea Amerio), G.S., M.A., E.A.; supervision, M.A., E.A. All authors have read and agreed to the published version of the manuscript.

Funding: This research received no external funding.

Institutional Review Board Statement: Not applicable.

Informed Consent Statement: Not applicable.

Data Availability Statement: Not applicable.

Conflicts of Interest: The authors declare no conflict of interest.

\section{References}

1. Yatham, L.N.; Chakrabarty, T.; Bond, D.J.; Schaffer, A.; Beaulieu, S.; Parikh, S.V.; McIntyre, R.S.; Milev, R.V.; Alda, M.; Vazquez, G. Canadian Network for Mood and Anxiety Treatments (CANMAT) and International Society for Bipolar Disorders (ISBD) recommendations for the management of patients with bipolar disorder with mixed presentations. Bipolar Disord. 2021, 23, 767-788. [CrossRef]

2. Swann, A.C.; Lafer, B.; Perugi, G.; Frye, M.A.; Bauer, M.; Bahk, W.-M.; Scott, J.; Ha, K.; Suppes, T. Bipolar mixed states: An international society for bipolar disorders task force report of symptom structure, course of illness, and diagnosis. Am. J. Psychiatry 2013, 170, 31-42. [CrossRef]

3. Angst, J.; Marneros, A. Bipolarity from ancient to modern times: Conception, birth and rebirth. J. Affect. Disord. 2001, 67, 3-19. [CrossRef]

4. Lorry, A.-C. De Melancholia et Morbis Melancholicis; Apud, P., Ed.; Guillelum Cavelier: Paris, France, 1765.

5. Maina, G.; Bertetto, N.; Domene Boccolini, F.; Di Salvo, G.; Rosso, G.; Bogetto, F. The concept of mixed state in bipolar disorder: From Kraepelin to DSM-5. J. Psychopathol. 2013, 19, 287-295.

6. Heinroth, J.C.A. Lehrbuch der Störungen des Seelenlebens: Oder, Der Seelenstörungen und Ihrer Behandlung, Vom Rationalen Standpunkt aus Entworfen; Vogel: Leipzig, Germany, 1818; Volume 1.

7. Griesinger, W. Die Pathologie und Therapie der Psychischen Krankheiten für Aerzte und Studirende; Verlag von Adolph Krabbe: Stuttgart, Germany, 1861.

8. Verdolini, N.; Agius, M.; Ferranti, L.; Moretti, P.; Piselli, M.; Quartesan, R. The state of the art of the DSM-5 "with mixed features" specifier. Sci. World J. 2015, 2015, 757258. [CrossRef] [PubMed]

9. Goodwin, F.K.; Jamison, K.R. Manic-Depressive Illness: Bipolar Disorders and Recurrent Depression; Oxford University Press: Oxford, UK, 2007.

10. Salvatore, P.; Baldessarini, R.J.; Centorrino, F.; Egli, S.; Albert, M.; Gerhard, A.; Maggini, C. Weygandt's on the Mixed States of Manic-Depressive Insanity: A translation and commentary on its significance in the evolution of the concept of bipolar disorder. Harv. Rev. Psychiatry 2002, 10, 255-275. [CrossRef] [PubMed]

11. Leonhard, K. Distribution of Endogenous Psychoses and Their Differentiated Aetiology; Akademie Verlag: Berlin, Germany, 1957. 
12. Koukopoulos, A.; Sani, G.; Ghaemi, S.N. Mixed features of depression: Why DSM-5 is wrong (and so was DSM-IV). Br. J. Psychiatry 2013, 203, 3-5. [CrossRef]

13. American Psychiatric Association. Diagnostic and Statistical Manual Mental Disorders: DSM-I, 1st ed.; American Psychiatric Association: Washington, DC, USA, 1952.

14. American Psychiatric Association. DSM-II: Diagnostic and Statistical Manual of Mental Disorders: DSM-II, 2nd ed.; American Psychiatric Association: Washington, DC, USA, 1975.

15. American Psychiatric Association. Diagnostic and Statistical Manual of Mental Disorders: DSM-III, 3rd ed.; American Psychiatric Association: Washington, DC, USA, 1980.

16. Ghaemi, S.N. Bipolar spectrum: A review of the concept and a vision for the future. Psychiatry Investig. 2013, 10, 218-224. [CrossRef]

17. American Psychiatric Association. Diagnostic and Statistical Manual of Mental Disorders: DSM-III-R, 3rd ed.; American Psychiatric Association: Washington, DC, USA, 1987.

18. American Psychiatric Association; Frances, A.; First, M.B.; Pincus, H.A. Diagnostic and Statistical Manual of Mental Disorders: $D S M-I V$, 4th ed.; American Psychiatric Association: Washington, DC, USA, 1994.

19. American Psychiatric Association. Diagnostic and Statistical Manual of Mental Disorders: DSM-IV-TR, 4th ed.; American Psychiatric Association: Washington, DC, USA, 2000.

20. Solé, E.; Garriga, M.; Valentí, M.; Vieta, E. Mixed features in bipolar disorder. CNS Spectr. 2017, 22, 134-140. [CrossRef] [PubMed]

21. Suppes, T.; Ostacher, M. Mixed features in major depressive disorder: Diagnoses and treatments. CNS Spectr. 2017, 22, 155-160. [CrossRef]

22. Pacchiarotti, I.; Kotzalidis, G.D.; Murru, A.; Mazzarini, L.; Rapinesi, C.; Valentí, M.; Anmella, G.; Gomes-da-Costa, S.; Gimenez, A.; Llach, C. Mixed features in depression: The unmet needs of diagnostic and statistical manual of mental disorders fifth edition. Psychiatr. Clin. 2020, 43, 59-68.

23. Perugi, G.; Angst, J.; Azorin, J.-M.; Bowden, C.L.; Mosolov, S.; Reis, J.; Vieta, E.; Young, A.H.; Group, B.-I.-M.S. Mixed features in patients with a major depressive episode: The BRIDGE-II-MIX study. J. Clin. Psychiatry 2015, 76, 12074. [CrossRef]

24. American Psychiatric Association. Diagnostic and Statistical Manual of Mental Disorders: DSM-5; American Psychiatric Association: Washington, DC, USA, 2013.

25. Hu, J.; Mansur, R.; McIntyre, R.S. Mixed specifier for bipolar mania and depression: Highlights of DSM-5 changes and implications for diagnosis and treatment in primary care. Prim. Care Companion CNS Disord. 2014, 16, PCC.13r01599. [CrossRef]

26. World Health Organization. International Statistical Classification of Diseases and Related Health Problems, 11th ed.; WHO: Geneva, Switzerland, 2019.

27. Maj, M. Mood disorders in ICD-11 and DSM-5. Die Psychiatr. 2013, 10, 24-29. [CrossRef]

28. Perugi, G. ICD-11 mixed episode: Nothing new despite the evidence. Bipolar Disord. 2019, 21, 376-377. [CrossRef] [PubMed]

29. Maj, M. Mixed states and rapid cycling: Conceptual issues and options for ICD-11. World Psychiatry 2012, 11, 65-68. [CrossRef] [PubMed]

30. Pacchiarotti, I.; Mazzarini, L.; Kotzalidis, G.D.; Valentí, M.; Nivoli, A.M.; Sani, G.; Torrent, C.; Murru, A.; Sanchez-Moreno, J.; Patrizi, B. Mania and depression. Mixed, not stirred. J. Affect. Disord. 2011, 133, 105-113. [CrossRef]

31. Miller, S.; Suppes, T.; Mintz, J.; Hellemann, G.; Frye, M.A.; McElroy, S.L.; Nolen, W.A.; Kupka, R.; Leverich, G.S.; Grunze, H. Mixed depression in bipolar disorder: Prevalence rate and clinical correlates during naturalistic follow-up in the Stanley Bipolar Network. Am. J. Psychiatry 2016, 173, 1015-1023. [CrossRef]

32. Koukopoulos, A.; Faedda, G.; Proietti, R.; D’Amico, S.; De Pisa, E.; Simonetto, C. Mixed depressive syndrome. Encephale 1992, 18, 19-21. [CrossRef] [PubMed]

33. Koukopoulos, A.; Koukopoulos, A. Agitated depression as a mixed state and the problem of melancholia. Psychiatr. Clin. N. Am. 1999, 22, 547-564. [CrossRef]

34. Koukopoulos, A.; Sani, G.; Koukopoulos, A.; Manfredi, G.; Pacchiarotti, I.; Girardi, P. Melancholia agitata and mixed depression. Acta Psychiatr. Scand. 2007, 115, 50-57. [CrossRef] [PubMed]

35. Sani, G.; Vöhringer, P.A.; Napoletano, F.; Holtzman, N.S.; Dalley, S.; Girardi, P.; Ghaemi, S.N.; Koukopoulos, A. Koukopoulos' diagnostic criteria for mixed depression: A validation study. J. Affect. Disord. 2014, 164, 14-18. [CrossRef]

36. Koukopoulos, A.; Sani, G. DSM-5 criteria for depression with mixed features: A farewell to mixed depression. Acta Psychiatr. Scand. 2014, 129, 4-16. [CrossRef] [PubMed]

37. Mineo, L.; Rodolico, A.; Spedicato, G.A.; Aguglia, A.; Bolognesi, S.; Concerto, C.; Cuomo, A.; Goracci, A.; Serafini, G.; Maina, G. Which Mixed Depression model? A comparison between DSM-5-defined mixed features and Koukopoulos' criteria. Bipolar Disord. 2021. [CrossRef] [PubMed]

38. Benazzi, F.; Akiskal, H.S. Delineating bipolar II mixed states in the Ravenna-San Diego collaborative study: The relative prevalence and diagnostic significance of hypomanic features during major depressive episodes. J. Affect. Disord. 2001, 67, 115-122. [CrossRef]

39. Benazzi, F. Which could be a clinically useful definition of depressive mixed state? Prog. Neuro-Psychopharmacol. Biol. Psychiatry 2002, 26, 1105-1111. [CrossRef]

40. Benazzi, F. Defining mixed depression. Prog. Neuro-Psychopharmacol. Biol. Psychiatry 2008, 32, 932-939. [CrossRef] 
41. Malhi, G.S.; Irwin, L.; Hamilton, A.; Morris, G.; Boyce, P.; Mulder, R.; Porter, R.J. Modelling mood disorders: An ACE solution? Bipolar Disord. 2018, 20, 4-16. [CrossRef]

42. Fagiolini, A.; Cuomo, A. On the centrality of mixed features in mood disorders: Listening to Kraepelin and Weygandt and moving forward. Bipolar Disord. 2017, 19, 704-705. [CrossRef]

43. Malhi, G.S.; Fritz, K.; Elangovan, P.; Irwin, L. Mixed states: Modelling and management. CNS Drugs 2019, 33, 301-313. [CrossRef]

44. Malhi, G.S.; Bell, E. Mixed states: An early warning sign of profound problems in our taxonomy? Acta Psychiatr. Scand. 2019, 139, 489-492. [CrossRef] [PubMed]

45. Cuomo, A.; Aguglia, A.; Aguglia, E.; Bolognesi, S.; Goracci, A.; Maina, G.; Mineo, L.; Rucci, P.; Sillari, S.; Fagiolini, A. Mood spectrum symptoms during a major depressive episode: Differences between 145 patients with bipolar disorder and 155 patients with major depressive disorder. Arguments for a dimensional approach. Bipolar Disord. 2020, 22, 385-391. [CrossRef]

46. Takeshima, M.; Oka, T. DSM-5-defined 'mixed features' and Benazzi's mixed depression: Which is practically useful to discriminate bipolar disorder from unipolar depression in patients with depression? Psychiatry Clin. Neurosci. 2015, 69, 109-116. [CrossRef]

47. Zimmermann, P.; Brückl, T.; Nocon, A.; Pfister, H.; Lieb, R.; Wittchen, H.-U.; Holsboer, F.; Angst, J. Heterogeneity of DSM-IV major depressive disorder as a consequence of subthreshold bipolarity. Arch. Gen. Psychiatry 2009, 66, 1341-1352. [CrossRef] [PubMed]

48. Swann, A.C.; Steinberg, J.L.; Lijffijt, M.; Moeller, G.F. Continuum of depressive and manic mixed states in patients with bipolar disorder: Quantitative measurement and clinical features. World Psychiatry 2009, 8, 166. [CrossRef] [PubMed]

49. Angst, J.; Gamma, A.; Benazzi, F.; Ajdacic, V.; Rössler, W. Does psychomotor agitation in major depressive episodes indicate bipolarity? Eur. Arch. Psychiatry Clin. Neurosci. 2009, 259, 55-63. [CrossRef] [PubMed]

50. Perugi, G.; Akiskal, H.S.; Micheli, C.; Toni, C.; Madaro, D. Clinical characterization of depressive mixed state in bipolar-I patients: Pisa-San Diego collaboration. J. Affect. Disord. 2001, 67, 105-114. [CrossRef]

51. Frazier, E.A.; Swenson, L.P.; Mullare, T.; Dickstein, D.P.; Hunt, J.I. Depression with mixed features in adolescent psychiatric patients. Child Psychiatry Hum. Dev. 2017, 48, 393-399. [CrossRef]

52. O'Donovan, C.; Alda, M. Depression preceding diagnosis of bipolar disorder. Front. Psychiatry 2020, 11, 500. [CrossRef] [PubMed]

53. Balázs, J.; Benazzi, F.; Rihmer, Z.; Rihmer, A.; Akiskal, K.K.; Akiskal, H.S. The close link between suicide attempts and mixed (bipolar) depression: Implications for suicide prevention. J. Affect. Disord. 2006, 91, 133-138. [CrossRef]

54. Diefenbach, G.J.; Woolley, S.B.; Goethe, J.W. The association between self-reported anxiety symptoms and suicidality. J. Nerv. Ment. Dis. 2009, 197, 92-97. [CrossRef]

55. Aguglia, A.; Cuomo, A.; Amerio, A.; Bolognesi, S.; Di Salvo, G.; Fusar-Poli, L.; Goracci, A.; Surace, T.; Serafini, G.; Aguglia, E. A new approach for seasonal pattern: Is it related to bipolarity dimension? Findings from an Italian multicenter study. Int. J. Psychiatry Clin. Pract. 2021, 25, 73-81. [CrossRef]

56. Young, R.C.; Biggs, J.T.; Ziegler, V.E.; Meyer, D.A. A rating scale for mania: Reliability, validity and sensitivity. Br. J. Psychiatry 1978, 133, 429-435. [CrossRef] [PubMed]

57. Bauer, M.S.; Crits-Christoph, P.; Ball, W.A.; Dewees, E.; McAllister, T.; Alahi, P.; Cacciola, J.; Whybrow, P.C. Independent assessment of manic and depressive symptoms by self-rating: Scale characteristics and implications for the study of mania. Arch. Gen. Psychiatry 1991, 48, 807-812. [CrossRef]

58. Angst, J.; Adolfsson, R.; Benazzi, F.; Gamma, A.; Hantouche, E.; Meyer, T.D.; Skeppar, P.; Vieta, E.; Scott, J. The HCL-32: Towards a self-assessment tool for hypomanic symptoms in outpatients. J. Affect. Disord. 2005, 88, 217-233. [CrossRef] [PubMed]

59. Altman, E.G.; Hedeker, D.; Peterson, J.L.; Davis, J.M. The Altman self-rating mania scale. Biol. Psychiatry 1997, 42, 948-955. [CrossRef]

60. Berk, M.; Malhi, G.S.; Cahill, C.; Carman, A.C.; Hadzi-Pavlovic, D.; Hawkins, M.T.; Tohen, M.; Mitchell, P.B. The Bipolar Depression Rating Scale (BDRS): Its development, validation and utility. Bipolar Disord. 2007, 9, 571-579. [CrossRef]

61. Hergueta, T.; Weiller, E. Evaluating depressive symptoms in hypomanic and manic episodes using a structured diagnostic tool: Validation of a new Mini International Neuropsychiatric Interview (MINI) module for the DSM-5 'With Mixed Features' specifier. Int. J. Bipolar Disord. 2013, 1, 21. [CrossRef]

62. Zimmerman, M.; Chelminski, I.; Young, D.; Dalrymple, K.; Martinez, J.H. A clinically useful self-report measure of the DSM-5 mixed features specifier of major depressive disorder. J. Affect. Disord. 2014, 168, 357-362. [CrossRef] [PubMed]

63. Zimmerman, M. Measures of the DSM-5 mixed-features specifier of major depressive disorder. CNS Spectr. 2017, 22, 196-202. [CrossRef]

64. First, M. Structured Clinical Interview for the DSM (SCID). In The Encyclopedia of Clinical Psychology; Wiley: Hoboken, NJ, USA, 2015; pp. 1-6. [CrossRef]

65. Sani, G.; Vöhringer, P.A.; Barroilhet, S.A.; Koukopoulos, A.E.; Ghaemi, S.N. The Koukopoulos Mixed Depression Rating Scale (KMDRS): An International Mood Network (IMN) validation study of a new mixed mood rating scale. J. Affect. Disord. 2018, 232, 9-16. [CrossRef]

66. Tavormina, G. Clinical utilisation of the "GT MSRS", the rating scale for mixed states: 35 cases report. Psychiatr. Danub. 2015, 27, 155-159.

67. Tavormina, G.; Franza, F.; Stranieri, G.; Juli, L.; Juli, M.R. Clinical utilisation and usefullness of the Rating Scale of Mixed States, (“Gt-Msrs"): A multicenter study. Psychiatr. Danub. 2017, 29, 365-367. 
68. Sachs, G.S.; Guille, C.; McMurrich, S.L. A clinical monitoring form for mood disorders. Bipolar Disord. 2002, 4, 323-327. [CrossRef] [PubMed]

69. Verdolini, N.; Hidalgo-Mazzei, D.; Murru, A.; Pacchiarotti, I.; Samalin, L.; Young, A.; Vieta, E.; Carvalho, A. Mixed states in bipolar and major depressive disorders: Systematic review and quality appraisal of guidelines. Acta Psychiatr. Scand. 2018, 138, 196-222. [CrossRef] [PubMed]

70. Baldessarini, R.J.; Faedda, G.L.; Offidani, E.; Vazquez, G.H.; Marangoni, C.; Serra, G.; Tondo, L. Antidepressant-associated mood-switching and transition from unipolar major depression to bipolar disorder: A review. J. Affect. Disord. 2013, 148, 129-135. [CrossRef]

71. Viktorin, A.; Lichtenstein, P.; Thase, M.E.; Larsson, H.; Lundholm, C.; Magnusson, P.K.; Landén, M. The risk of switch to mania in patients with bipolar disorder during treatment with an antidepressant alone and in combination with a mood stabilizer. Am. J. Psychiatry 2014, 171, 1067-1073. [CrossRef]

72. Grunze, H.; Vieta, E.; Goodwin, G.M.; Bowden, C.; Licht, R.W.; Azorin, J.-M.; Yatham, L.; Mosolov, S.; Möller, H.-J.; Kasper, S. The World Federation of Societies of Biological Psychiatry (WFSBP) guidelines for the biological treatment of bipolar disorders: Acute and long-term treatment of mixed states in bipolar disorder. World J. Biol. Psychiatry 2018, 19, 2-58. [CrossRef]

73. Stahl, S.M.; Morrissette, D.A.; Faedda, G.; Fava, M.; Goldberg, J.F.; Keck, P.E.; Lee, Y.; Malhi, G.; Marangoni, C.; McElroy, S.L. Guidelines for the recognition and management of mixed depression. CNS Spectr. 2017, 22, 203-219. [CrossRef]

74. Goodwin, G.; Haddad, P.; Ferrier, I.; Aronson, J.; Barnes, T.; Cipriani, A.; Coghill, D.; Fazel, S.; Geddes, J.; Grunze, H. Evidencebased guidelines for treating bipolar disorder: Revised third edition recommendations from the British Association for Psychopharmacology. J. Psychopharmacol. 2016, 30, 495-553. [CrossRef]

75. Fountoulakis, K.N.; Grunze, H.; Vieta, E.; Young, A.; Yatham, L.; Blier, P.; Kasper, S.; Moeller, H.J. The International College of Neuro-Psychopharmacology (CINP) treatment guidelines for bipolar disorder in adults (CINP-BD-2017), part 3: The clinical guidelines. Int. J. Neuropsychopharmacol. 2017, 20, 180-195. [CrossRef]

76. Malhi, G.S.; Bell, E.; Bassett, D.; Boyce, P.; Bryant, R.; Hazell, P.; Hopwood, M.; Lyndon, B.; Mulder, R.; Porter, R. The 2020 Royal Australian and New Zealand College of Psychiatrists clinical practice guidelines for mood disorders. Aust. N. Z. J. Psychiatry 2021, 55, 7-117. [CrossRef] [PubMed]

77. Müller-Oerlinghausen, B. Arguments for the specificity of the antisuicidal effect of lithium. Eur. Arch. Psychiatry Clin. Neurosci. 2001, 251, 72-75. [CrossRef] [PubMed]

78. Sani, G.; Swann, A.C. Mixed states: Historical impact and evolution of the concept. Psychiatr. Clin. 2020, 43, 1-13.

79. Maj, M.; Stein, D.J.; Parker, G.; Zimmerman, M.; Fava, G.A.; De Hert, M.; Demyttenaere, K.; McIntyre, R.S.; Widiger, T.; Wittchen, H.U. The clinical characterization of the adult patient with depression aimed at personalization of management. World Psychiatry 2020, 19, 269-293. [CrossRef] 